Article

\title{
Deliberative Mini-Publics and the European Green Deal in Turbulent Times: The Irish and French Climate Assemblies
}

\author{
Diarmuid Torney \\ School of Law and Government, Dublin City University, Ireland; E-Mail: diarmuid.torney@dcu.ie
}

Submitted: 19 April 2021 | Accepted: 6 September 2021 | Published: 30 September 2021

\begin{abstract}
Innovative forms of deliberative democracy are gaining traction in governing responses to climate change in Europe and beyond. Proponents of deliberative democracy have drawn attention to its particular suitability for shaping responses to environmental challenges. Citizen engagement and participation is also a prominent feature of the European Green Deal. This article considers the relationship between turbulence and deliberative democracy in the context of climate transitions, exploring when and how such democratic innovations are likely to generate turbulence in the governance of climate transitions. A framework is developed that focuses on three important sets of characteristics of deliberative mini-publics (DMPs): (a) the nature of their formal mandates and the ways in which climate change is framed as a policy problem; (b) the nature of participation and the degree to which the participants are empowered to shape the deliberative processes in which they participate; and (c) the degree to which DMPs are coupled with relevant policymaking processes. This framework is used to explore two recent and high-profile cases of a particular type of DMP: citizens' assemblies in Ireland and France. The article contributes to the literatures on turbulent governance and deliberative democracy by reflecting on key dimensions of DMPs from the analytical perspective of turbulent governance.
\end{abstract}

\section{Keywords}

climate change; deliberative democracy; democratic mini-public; European Green Deal; turbulence

\section{Issue}

This article is part of the issue "Climate Governance and the European Green Deal in Turbulent Times" edited by Claire Dupont (Ghent University, Belgium) and Diarmuid Torney (Dublin City University, Ireland).

(C) 2021 by the author; licensee Cogitatio (Lisbon, Portugal). This article is licensed under a Creative Commons Attribution 4.0 International License (CC BY).

\section{Introduction}

Citizen engagement, participation, and deliberation are prominent features of the European Green Deal (EGD). The Commission's 2019 EGD communication articulates its aim as being "to transform the EU into a fair and prosperous society, with a modern, resource-efficient and competitive economy where there are no net emissions of greenhouse gases in 2050 and where economic growth is decoupled from resource use" (European Commission, 2019, p. 2). A European Climate Pacta central element of the EGD proposal-aims to "build on the Commission's on-going series of citizens' dialogues and citizens' assemblies across the EU, and the role of social dialogue committees" (European Commission, 2019, p. 23).
The importance of citizen participation in the EGD and, more broadly, in the transition to a climate neutral and resilient future, is driven at least in part by the need to ensure that justice and fairness are placed at the centre of the transition. The costs and benefits of transition are distributed in deeply unequal ways across space and time, as are existing opportunities to participate in shaping climate transitions. The European Commission's EGD communication notes prominently that the envisaged transition must be:

Just and inclusive. It must put people first, and pay attention to the regions, industries and workers who will face the greatest challenges. Since it will bring substantial change, active public participation and confidence in the transition is paramount if policies 
are to work and be accepted. (European Commission, 2019, p. 1)

Against this backdrop, innovative forms of deliberative democracy are gaining traction in governing responses to climate change. This phenomenon forms part of a broader "deliberative wave" (OECD, 2020) in which the use of deliberative processes is growing in prevalence and prominence across countries and policy areas. Building on a longer line of scholarship advocating deliberative democracy (e.g., Dryzek, 1990; Fishkin, 1991), proponents of deliberative democracy have drawn attention to its particular suitability for shaping responses to environmental challenges, which are characterised by conflicting interests, values and worldviews, complexity, trade-offs, and long-time horizons that stretch beyond one electoral cycle (e.g., Blue, 2015; Niemeyer, 2013; Smith, 2003; Stevenson \& Dryzek, 2014). Rather than simply aggregating atomized preferences of the population through elections or opinion polling, the process of deliberation can serve to transform the preferences of participants by exposing them to a wide variety of views and engaging them in conversation with those whose views they may not share. Niemeyer (2013) argues that deliberative forums enable participating citizens to consider the interest of non-human agents, and that deliberation has the potential to attune participants to complexity as well as to take a long-term view on global environmental issues.

Within the broader field of deliberative democracy, a significant literature has developed around the use of so-called "deliberative mini-publics" (DMPs), defined by Goodin and Dryzek (2006, p. 220) as democratic innovations involving ordinary citizens in "groups small enough to be genuinely deliberative, and representative enough to be genuinely democratic." According to Farrell et al. (2019), DMPs are characterised by two core design features: (a) they are deliberative in the sense that participants reach conclusions having received relevant information and engaged in a careful and open discussion; and (b) they are representative in that participants are selected to be representative, as far as possible, of the wider population.

The broader political and social landscape presents challenges for climate transitions. Brexit, the Covid-19 pandemic, and in a climate context resistance from central and eastern member states to ambitious policy agendas, as well as a widespread perception that democracy is in crisis (Norris \& Inglehart, 2019) all complicate the pathway for implementation of the EGD. Populist backlash has been increasingly evident in a range of western democracies, with action on climate change drawing particularly strong critique for being an elitist or unjust project. The concept of turbulent governance has been used to capture the accumulation of challenges (Ansell \& Trondal, 2018; see also Dobbs et al., 2021). Turbulence is distinguished from crisis in the sense that it is a normal and enduring feature of the contemporary governance landscape-a condition or a dysfunction-and as something to be managed or withstood.

The aim of this article is to situate the growth in DMPs for framing climate transitions within the context of turbulent governance. Such democratic innovations can be seen as either a response to turbulent governance or as a cause of turbulence in the broader climate governance landscape. In this context, this article focuses more narrowly on DMPs as a cause of turbulence in climate change governance. It connects the concept of turbulent governance to the literature on DMPs and seeks to answer the question: To what extent and under what conditions can DMPs lead to turbulence in the governance of climate transitions?

The article distinguishes three key characteristics of DMPs: (a) the nature of their formal mandates and the ways in which climate change is framed as a policy problem; (b) the nature of participation and the degree to which the participants are empowered to shape the deliberative processes in which they participate; and (c) the degree to which DMPs are coupled with relevant policymaking processes. These characteristics are then used as a framework to explore two recent and highprofile cases of a particular type of DMP: citizens' assemblies focused on climate change conducted in EU member states, namely the Irish Citizens' Assembly, which deliberated on climate change along with four other topics, and the French Citizens Convention for Climate (Convention Citoyenne pour le Climat).

The article proceeds as follows: Section 2 sets out the article's case selection and approach. Section 3 introduces the concept of turbulent governance and relates it to the literature on DMPs. Section 4 undertakes an empirical analysis of the two selected cases mentioned above to provide an analytical mapping of emerging practices. Section 5 discusses the findings and reflects on the extent to which the two DMPs have led to turbulence in the governance of climate transitions. Section 6 concludes and identifies broader lessons for climate transitions and the EGD.

\section{Case selection and Approach}

DMPs range in size from small processes such as citizens' juries (typically 15-30 participants), citizens' councils (typically 15 participants), and consensus conferences (typically 16 participants), to larger processes such as citizens' assemblies (typically 90-150 participants), citizens' dialogues (typically 150 participants), and deliberative surveys (typically more than 200 participants). DMPs share certain features that distinguish them from other forms of citizen participation (Brown, 2006; Farrell et al., 2019): (a) They provide participants with access to a range of relevant information on the topic in question and, importantly, provide adequate time and space for participants to deliberate with their fellow citizens; (b) they limit interest group representatives to participation as expert group members and possible steering 
group members; (c) they feed into policy processes, but they have no authority to make legally binding decisions; and (d) they address both public officials and the general public. Mini-publics are usually representative of the "maxi-public," that is, the wider population from which the participants are drawn.

The empirical focus in this article is more narrowly on citizens' assemblies, considered to be the most robust and elaborate form of DMP (Escobar \& Elstub, 2017). A range of European countries have implemented national citizens' assemblies focused, in part or in full, on climate change, including Ireland, France, the UK, Scotland, Denmark, Finland, and Germany. A range of smaller scale deliberative processes have been implemented at city or local level, such as in the UK, Hungary, and Poland. These processes exhibit significant national variation in terms of their establishment, design, scope, operation, outcomes, and impact.

The empirical analysis in Section 4 focuses on the Irish Citizens' Assembly, which deliberated on climate change along with four other topics, and the French Citizens Convention for Climate. Both fulfil the core criteria of DMPs set out in the introduction, namely that they were deliberative and representative, involved extended deliberation on the topic of climate change, and consisted of representative random samples of the national population. The French and Irish cases were selected for analysis furthermore on the basis that, at the time of writing, enough time has elapsed to be able to begin to analyse their relationship with the broader policy system and the extent to which they can be considered a cause of turbulence in climate transitions. The empirical analysis draws on publicly available sources and existing research-including that conducted by the author on the Irish case-regarding the design, implementation, and outcomes of these two national citizens' assemblies. Rather than conducting new empirical research, the aim of the analysis is to explore the plausibility of the analytical framework and open new avenues for research.

\section{Turbulent Governance and Deliberative Mini-Publics in the Context of Climate Transitions}

Turbulence provides a useful conceptual entry point to analysing the role of DMPs in the context of the EGD. Ansell and Trondal (2018, p. 53) define turbulence as "situations where events, demands, and support interact in highly variable, inconsistent, unexpected and unpredictable ways." Elsewhere they characterise turbulence as the "increasingly volatile context for complex problemsolving" (Ansell et al., 2020, p. 3). Ansell and Trondal (2018, p. 46) distinguish between three types of turbulence: (a) organisational turbulence, which covers turbulence within organisations themselves; (b) environmental turbulence, which includes sources of turbulence from the broader environment; and (c) scalar turbulence, which includes the turbulence caused by activities at one governance level that spill over to another level such as when policy solutions at one level create problems at another. In another contribution to this thematic issue, Dobbs et al. (2021) suggest the need to expand the conceptualisation of turbulence developed by Ansell and colleagues to include policy turbulence, which they define as "where there is substantial policy conflict or incoherence, e.g., due to multiple related policies in conflict, a substantive policy gap, or potentially a new policy that is exceptionally innovative or overhauls the regime" (Dobbs et al., 2021, p. 319)

How does turbulence manifest itself in the governance of climate transitions? Elsewhere in this thematic issue, Dobbs et al. (2021) develop the concept of turbulence in the context of the EGD. Brexit, the Covid-19 pandemic, Euroscepticism, political upheaval in member states, and the broader international landscape can all be identified as sources of environmental turbulence for the EGD. Moreover, the EGD itself is a potential source of turbulence, since it entails significant and potentially disruptive changes across a wide range of policy arenas. In terms of organisational turbulence, examples include reforms within the European Commission such as the creation of DG Clima as well as the challenges faced in the appointment of a new Commission president in 2019. For scalar turbulence, the multilevel character of the EU governance system and particularly the fact that many of the areas of relevance to the EGD are shared competences between the Union and member state levels increase the prospects of scalar turbulence.

How can we situate the relationship between DMPs and turbulent governance in the context of climate transitions? As a form of institutional innovation, DMPs can be conceptualised as both a response to turbulence and themselves a cause of turbulence. By opening up channels for citizen participation, DMPs can potentially serve as a response to environmental turbulence such as pervasive distrust of political institutions, disinformation and rising Euroscepticism (Norris \& Inglehart, 2019). In the case of the scale of transformative change envisaged in the EGD, DMPs can serve as institutional mechanisms to engage diverse publics-including marginalised and hard-to-reach sections of society. DMPs can also themselves be a cause of turbulence. If their recommendations push the boundaries of what is deemed to be politically feasible or acceptable, they may be a source of environmental turbulence if they disrupt established interest groups or the political status quo. They may also serve as sources of policy turbulence or scalar turbulence by proposing recommendations that disrupt the status quo in other policy arenas or at other scales of governance.

The focus of this article is on DMPs as a source of turbulence in the governance of climate transitions. Whether and to what extent this is the case is likely to be shaped by their specific institutional characteristics as well as the broader context in which they are commissioned and operate. Here, I identify three key characteristics of DMPs that I suggest shape the degree to which DMPs may be a cause of turbulence in climate 
governance: (a) the nature of their formal mandates and the range of information and material to which participants are given access; (b) the nature of participation and the degree to which the participants are empowered to shape the deliberative processes in which they participate; and (c) the degree to which DMPs are coupled with relevant policymaking processes.

\subsection{Mandate and Framing}

A first important characteristic in terms of turbulent governance is the mandate of the DMP and how the topic is framed. According to a recent OECD report, the question for deliberation ought to be broad enough to allow for numerous possible recommendations, but not so broad as to lead to side-tracking (OECD, 2020, p. 85). Deliberative processes arguably work best when framed around a distinct, specific policy question that needs to be answered (Devaney, Brereton, et al., 2020). Narrower framings can facilitate clear results over shorter timeframes, whereas broader framings can incorporate a wider range of topics but may be slower and produce less clear-cut recommendations (Bryant \& Stone, 2020). Other things being equal, more specific recommendations are harder to ignore and therefore are more likely to generate turbulence in the wider governance system.

A related characteristic concerns the way in which climate change is framed as a policy problem in the context of a DMPs. The deliberative process is underpinned by the provision of relevant information on the topic under consideration, and usually involves an overview of the topic and diagnosis of the problem at hand, followed by more detailed information and outlining of possible solutions (Gerwin, 2018). As Capstick et al. (2020) argue, there is no "neutral" way of framing climate change. Diversity of information sources is important, as is giving participants control over which sources and types of information they wish to access (newDemocracy, 2019). The greater the range of information sources, the less constrained is the nature and content of this information by dominant interests and perspectives, and the greater the control that participants have over the material to which they are exposed, the more potentially transformative and disruptive the DMP may be.

\subsection{Agency of Participants}

Who participates in a DMP and to what degree the participants themselves are provided with opportunities to shape the processes in which they participate constitute another important set of characteristics with respect to turbulent governance. The representativeness and inclusiveness of DMPs are key factors in the legitimacy of these processes (Olsen \& Trenz, 2016; Pow, 2021). Some models of deliberation such as enclave deliberation emphasise the benefits of dedicated forums for disempowered groups (Brown, 2006; Karpowitz et al., 2009), but DMPs are characterised by random selection that gives each member of the public an equal chance of participation. This can take the form of "pure" random selection and stratified random selection in which the sample reflects important characteristics of the wider population such as gender, age, socio-economic status, ethnicity, geography, etc. (Farrell et al., 2019). The size of the process is also an important characteristic, particularly for stratified sampling: The larger the number, the more likely it is to capture important demographic characteristics of the wider population.

The degree to which participants in a DMP are empowered to shape the process is an important crosscutting characteristic. One aspect of this concerns the mandate and information to which participants are exposed. The greater the scope for participants themselves to share these aspects of the process, the more potentially transformative the process and its outputs may be. A further important dimension concerns the decision-making procedures used to arrive at outputs, and what form those outputs should take, for example a series of recommendations on which the members vote, a narrative report, or some other form.

\subsection{Policy Coupling and Integration}

The degree to which a DMP is coupled with the broader policy system is an important institutional characteristic in terms of its potential to generate turbulence for the wider governance system. One relevant institutional characteristic concerns the commissioning authority. A DMP can be commissioned by government, by civil society, or by another entity such as an academic institution. We can distinguish further between commission by the executive and legislative branches of government. DMPs commissioned by policymakers are likely to be more tightly coupled to the policymaking process (Setälä, 2017; Thompson, 2019). Farrell et al. (2019) advocate for an independent chair and professional secretariat, and that DMPs should be kept at arm's length from government thereby maintaining a credible level of independence and allowing for citizen-led approaches to designing the agenda and process.

Another important dimension of policy coupling concerns the outputs of a DMP and how those outputs are integrated into the wider policymaking process. This is among the most challenging dimensions of DMPs from both an analytical and practice perspective. There is no consensus in the literature on this issue, with a recent review by the OECD arguing that "research that links the outcomes of these processes to citizens' perceptions of their trust, fairness, and effectiveness is also lacking" (OECD, 2020, p. 165). Gerwin (2018) argues that DMP recommendations should be binding, which was the case for city-level citizens' assemblies held in Poland. In the case of the British Columbia Citizens' Assembly, the government committed in advance to put the assembly's recommendations to a referendum (Bua, 2019; Setälä \& Smith, 2018), but many other scholars suggest that 
recommendations should not be binding. This, however, creates the risk of cherry-picking by decision-makers (Font et al., 2018). Farrell et al. (2019) recommend that there should be clear guidelines in advance on how recommendations will be dealt with.

The more empowered a DMP is in both of these respects-in terms of the role of the participants in shaping the outputs and recommendations and the degree of pre-commitment to implementation-the more likely the process is to generate turbulence for the wider policy system. The broader political context is also an important factor. The prominence of climate change on the policy agenda and the mobilisation of societal stakeholders either in support of, or in opposition to, the outputs of a DMP will shape the impact that such processes have on the wider policy system.

Table 1 summarises the findings of the above discussion, which has drawn attention to the importance of mandates and framing, participation and agency, and policy coupling in shaping the how DMPs relate to turbulent governance in the context of climate transitions. DMPs with non-specific mandates, in which the participants are given limited scope to shape the process, and which are only loosely coupled and integrated into broader policymaking processes are less likely to cause turbulence in the governance of climate transitions. By contrast, DMPs that address specific mandates, give participants a strong role in shaping the process, and are tightly coupled with broader policy processes are more likely to be a source of turbulence for the broader governance landscape. The next section uses the framework developed in this section to structure an analysis of two of the most high-profile climate-focused national DMPs to date, in Ireland and France.

\section{Deliberative Mini-Publics and Climate Governance:} Evidence From the Irish and France Climate Assemblies

The analysis in this section focuses on national level citizens' assemblies on climate change in Ireland (2016-2018) and France (2019-2020). The analysis focuses on two early examples of national-level processes that fulfil the criteria of both DMPs and the narrower category of citizens' assemblies. The discussion below considers each case study, structuring the analysis around the framework developed in Section 3.

\subsection{The Irish Citizens' Assembly on Climate Change}

In Ireland, a Citizens' Assembly was established in 2016 to consider five topics, one of which was climate change. It met on 12 occasions between October 2016 and April 2018. Its deliberations on climate change took place over two weekends in September and November 2017. The most high-profile of the five topics-and the one for which the assembly is arguably best known-was the politically controversial topic of abortion. Climate change was not part of its original remit as set out in the parliamentary resolution providing for its establishment; rather, it was added as a result of a Green Party amendment to the resolution (Devaney, Torney, et al., 2020).

The mandate of the Citizens' Assembly on the topic of climate change was exceptionally broad. This was set out in the terms of reference, which were set down in a resolution of both Houses of Parliament. The question to be addressed with respect to climate change was "how the State can make Ireland a leader in tackling climate change" (Citizens' Assembly, 2018, p. 48). No timeframe (e.g., 2030 or 2050) was set out and there was no indication of what being a "leader" might entail. This provided an exceptionally broad canvas for the assembly and constrained its ability to feed into specific climate policy processes. There was no mandate, for example, to shape the country's 2030 climate change targets or pathways towards those targets, nor was there an opportunity to shape a specific climate change policy framework such as the state's statutory National Mitigation Plan or National Energy and Climate Plan.

The work programme divided the topic of climate change into a broad overview of climate change science and policy, sectoral consideration of energy, transport, and agriculture, food and land use, as well as a session on international perspectives on climate leadership featuring contributions from Scotland and Denmark (Citizens' Assembly, 2018, Chapter 3). The scope of the assembly was constrained by the limited time devoted to the climate change topic. While the assembly met for 12 weekends in total over a period of 18 months, only two of those meetings were devoted to the topic of climate change. This included a total of 26 hours of listening, discussion and deliberation, with presentations from $15 \mathrm{cli}$ mate change experts and six individuals championing low carbon transition (Devaney, Torney, et al., 2020). Within

Table 1. Core characteristics of DMPs and their relevance for turbulence.

\begin{tabular}{lll}
\hline & Design characteristics & Characteristics likely to generate turbulence \\
\hline Mandate and framing & Specific vs. broad mandate & Specific mandate \\
\cline { 2 - 3 } & Constrained vs. unconstrained framing & Unconstrained framing \\
\hline Participation and agency & Agency of participants & Strong role for participants \\
\hline Policy coupling and integration & Commissioning authority and its role & Independence from commissioning authority \\
\cline { 2 - 3 } & $\begin{array}{l}\text { Degree of pre-commitment to } \\
\text { implementation }\end{array}$ & High degree of pre-commitment \\
\hline
\end{tabular}


each sectoral section, this was limited to typically two expert speakers, with no speakers invited from interest groups such as business groups or NGOs. Separate categories of speakers were identified: experts and "exemplars" of climate action. The effect of this constraint was to limit the breadth of evidence presented to the participants, potentially therefore limiting the breadth of their recommendations.

The assembly's 99 participants were selected by random sample stratified by a range of demographic characteristics including age, gender, social class, and region (Citizens' Assembly, n.d.-b). A steering group composed of the chair, secretariat, and a representative group of members provided a channel for members to provide input to shaping the process (Citizens' Assembly, 2018, Chapter 2). The extent to which the participants were able to shape the process through this channel is unclear. A draft ballot paper was prepared by the chair and secretariat, with input from the expert advisory group and steering group, and then put to the full membership for discussion and approval. Once the ballot paper was approved, voting on each of the 13 recommendations was by secret ballot. All recommendations were endorsed by $80 \%$ or more, including politically contentious recommendations to increase the level of an existing carbon tax, to place a tax on greenhouse gas emissions from agriculture, and to end subsidies for peat extraction (Citizens' Assembly, 2018). The assembly's recommendations became a focal point for policy entrepreneurs, particularly within civil society, seeking to strengthen Ireland's response to climate change. Welcoming the formal publication of the assembly's report on climate change in April 2018, the Stop Climate Chaos coalition hailed the recommendations as "a mandate for revolutionising Ireland's climate policy" (Stop Climate Chaos, 2018).

In terms of coupling and integration with the policy process, the assembly was established by resolution of both Houses of Parliament, but the commissioning authority had no role in the running of the process. An independent secretariat composed of staff seconded from the Department of the Taoiseach (Prime Minister) was tasked with supporting an independent chair (retired Supreme Court Judge Mary Laffoy), who was appointed by government to lead the process. An expert advisory group was composed of experts in climate change science and policy, and deliberative democracy provided external advice to the chair and secretariat. The resolution mandated the creation of a special parliamentary committee to examine the assembly's recommendations on only one of the five topics under consideration, namely Ireland's constitutional ban on abortion. The parliamentary resolution establishing the assembly required for the other four topics only that parliament would respond to each recommendation (Citizens' Assembly, n.d.-a). Despite not being required, in the case of the climate change topic a similar model to that required for follow-up on the abortion topic was adopted, and a special parliamentary committee was established to consider the recommendations. This special committee-the Joint Oireachtas (Parliamentary) Committee on Climate Action-was established in July 2018. Over a period of approximately six months, the committee considered the recommendations of the assembly -in greater detail than the assembly had been able to, a process that included calling a range of expert witnesses.

The parliamentary committee published its own recommendations in March 2019 (Houses of the Oireachtas, 2019). These recommendations largely amplified and developed the assembly's recommendations, including developing the assembly's recommendation to place climate change at the centre of policymaking into a proposal to comprehensively revise the state's 2015 framework climate law. This recommendation was subsequently incorporated as the central climate governance commitment of a government Climate Action Plan published in June 2019 (DCCAE, 2019). Following a lengthy legislative process that was interrupted by a general election in February 2020, the Climate Action and Low Carbon Development (Amendment) Bill was signed into law in July 2021. However, not all of the assembly's recommendations were implemented. The most significant exception was the assembly's recommendation to place a GHG tax on emissions from agriculture. Accounting for over one-third of Ireland's GHG emissions, the debate on the role of the agriculture sector in addressing climate change is particularly contentious. The assembly's recommendation was not endorsed by the parliamentary committee, which recommended only that the topic be given further consideration.

Taking a longer-term perspective, the most consequential impact of the assembly's recommendations may turn out to be the revision of the climate law. The amended climate law puts in place an enhanced governance framework, with binding five-year carbon budgets and stronger accountability provisions. This framework may indeed introduce significant turbulence into the broader governance landscape, moving climate change concerns closer to the centre of policymaking. The broader context, including the publication of the IPCC report on global warming of 1.5 degrees as well as a rise in societal awareness of the climate crisis, illustrated for example in the school strikes for climate, played a key role in creating the conditions for these significant developments. The assembly itself and its recommendations are best characterised as an inspiration or spur that set this process rather than its proximate cause.

\subsection{The French Citizens Convention for Climate}

The French Citizens Convention for Climate was widely seen as a response to the gilets jaunes protests against a rise in fuel tax (Eymard, 2020). An initial response to the protests, the grand débat convened by President Macron, convened 18 regional citizen conferences, each 
inviting about a hundred randomly selected citizens to deliberate for a day and a half (Giraudet et al., 2021). However, the grand débat was widely criticised as being a smoke screen as well as for "not following the basic standards of deliberation design" (Ehs \& Mokre, 2021). The Citizens Convention for Climate was formally initiated in July 2019 by a letter from the prime minister. It convened for the first time in October 2019 and met over seven 2.5-day sessions between October 2019 and June 2020.

In terms of its mandate, the convention was commissioned by the executive and was tasked with deliberating on how to define a series of measures to achieve a reduction of at least $40 \%$ in greenhouse gas emissions by 2030 (compared to 1990) in keeping with the principle of social justice (Citizens Convention for Climate, n.d.). As such, it was a relatively specific mandate, with a defined timeframe (2030) and predefined level of ambition in terms of the decarbonisation target (40\%). The reference to social justice stemmed from the convention's origins in the gilets jaunes protests. The specificity of the mandate arguably provided greater scope for the convention to contribute to near-term climate action policies, though how far the recommendations would go in delivering on the $40 \%$ target was not quantified at the time (Giraudet et al., 2021).

A wide range of speakers were invited, including those considered to be neutral experts as well as those invited to present a particular perspective. A review of the convention conducted by a range of independent researchers who observed the process argues that the group of experts tasked with informing the participants shaped the process and its recommendations (Giraudet et al., 2021). According to this assessment, the way in which the debates were structured by the organisers meant that experts and speakers with opposing views were rarely given the opportunity to challenge each other's evidence. The assessment by the group of observers also noted that the degree to which the invited experts shaped the deliberations varied across different thematic areas, but that overall it was significant (Giraudet et al., 2021).

The convention consisted of 150 participants, who were selected using stratified random sampling. These participants were stratified in order to be representative of the diversity of the French society on the basis of socio-demographic criteria: gender, age, level of education, place of residence (urban, suburbs, rural, etc.), geographical area (including overseas territories), and socio-professional category (Citizens Convention for Climate, n.d.). The governance of the convention was structured around five groups: (a) a governance committee tasked with setting the agenda and rules, consisting of representatives of think tanks, trade unions, business, government officials, and academics with relevant expertise; (b) A group of three guarantors nominated by the National Assembly, the Senate, and the Economic, Social and Environmental Council; (c) a group of 19 experts tasked with providing technical background on climate policies and technologies; (d) a group of six legal experts tasked with providing feedback on the participants' recommendations; and (e) a consortium of deliberation facilitators.

According to Giraudet et al. (2021), the most distinctive feature of the French convention when compared to other citizens' assemblies on climate change was its approach based on "co-construction" between citizens and experts. Citizens were split into five thematic working groups: "consuming," "travelling," "housing," "eating," and "producing and working." Recommendations were prepared by sub-groups of the whole membership with support from the committee of legal experts and specialists with expertise in decarbonisation (Saujot et al., 2020, p. 6). In addition to the formal deliberations, some of the members met with civil society and policymakers outside of the formal process and organised debates themselves, leading Saujot et al. $(2020$, p. 6) to describe the process as "a co-construction process by the 150 citizens in interaction with several groups of actors both within and outside the convention." Indeed, the term "co-construction" was included in the letter from the prime minister commissioning the process.

In terms of policy coupling and integration, as noted above, the convention was commissioned by the executive branch of government. The Economic, Social and Environmental Council was in charge of overseeing the organisation of the event and of ensuring its independence, including that of the governance committee. Nonetheless, it was strongly coupled with the policy system from the start by virtue of the fact that President Macron committed to submitting the convention's recommendations "unfiltered" to a referendum or to parliament, or to direct regulatory application (Eymard, 2020). As Giraudet and colleagues note, the meaning and implications of the "unfiltered" stipulation were never fully clear. One interpretation placed an obligation on government to implement the recommendations regardless of their content, but an alternative interpretation placed an obligation on the convention to produce recommendations that were readily implementable (Giraudet et al., 2021).

The convention's recommendations consisted of 149 measures in total. Of these, three were selected by the participants to be proposed for referendum. These were two constitutional reforms and the recognition of ecocide as a crime. In a speech delivered a week after the publication of the convention's recommendations, President Macron committed to supporting 146 out of 149 of the recommendations but declined to accept three, namely amending the preamble of the constitution, imposing a $4 \%$ tax on corporate dividends, and reducing speed limits on motorways (Giraudet et al., 2021). In February 2021, the French government published the Climate and Resilience Bill as its response to the convention's recommendations. This bill was judged by the Convention's members themselves as an 
insufficient response (Huffpost, 2021). As the bill progressed through the legislative process it was further weakened. The final version, agreed by the National Assembly and the Senate in July 2021 was criticised by civil society as being inconsistent with the original recommendations of the Convention (Bauer-Babef, 2021).

Overall, the combination of a relatively tightlydefined mandate and a process that granted significant agency to the participants themselves through a co-created process provided the basis for a set of recommendations that have the potential to create significant turbulence in France's climate governance landscape. President Macron's commitment in advance to submit the convention's recommendations "unfiltered" to either a referendum, to parliament, or to direct regulatory application created the possibility of significant turbulence, but it was revoked in the end. Macron rejected three of the convention's recommendations from the start, and the implementing legislation lessened the strength of others.

\section{Discussion}

This article has explored the conditions under which democratic innovations such as DMPs are likely to cause turbulence in the governance of climate transitions. Drawing on the deliberative democracy literature, I identified a set of DMP characteristics of relevance, centred upon: (a) the nature of their formal mandates and the ways in which climate change is framed as a policy problem; (b) the degree to which participants are empowered to shape the deliberative processes in which they participate; and (c) the degree to which DMPs are coupled with relevant policymaking processes. Two recent nationallevel citizens' assemblies have been discussed, focused on climate change in Ireland and France to explore the utility of this framework. The previous analysis shows considerable diversity among these processes in respect of all three categories across the two cases, which is summarised in Table 2.

In terms of mandates and framing, there was significant variation. The French convention was given a relatively specific mandate, tasked with considering how to achieve $40 \%$ decarbonisation by 2030 in a spirit of social justice. By contrast, the mandate in the case of the Irish citizens' assembly was much more open-ended, without a specified timeframe or decarbonisation target. The cir- cumstances in which the two processes were established varied. In the Irish case, climate change was added to the agenda of an assembly focused primarily on the topic of abortion, almost as an after-thought. In the French case, by contrast, the convention was widely seen as a government response to the Gilet jaunes protests against an unpopular fuel tax.

The two assemblies also varied in terms of the agency given to the participants themselves. The French convention operated in a co-creative manner, with a comparatively strong role for the participants themselves to shape the process. The Irish assembly was, by contrast, run in a way that did not give as much agency to the participants. The manner in which the participants were involved in designing (as opposed to merely voting on) those outputs also differed.

In terms of policy coupling and integration, while both processes were commissioned by government, they were governed in ways that were more or less at armslength from government, though the arrangements differed in each case. Each of the processes reported to the commissioning branch of government, but the degree of pre-commitment by government to considering the recommendations varied considerably. In the Irish case, the assembly's recommendations were considered by parliament, with little explicit pre-commitment except to consider them. By contrast, the French president pre-committed to submitting the recommendations "unfiltered" either to referendum or to parliament.

According to the expectations developed in Section 2, the contrasting characteristics of the French and Irish DMPs ought to have resulted in limited turbulence in the Irish case and significant turbulence in the French case. This is not how the story played out. In the Irish case, albeit over a longer timeframe, the Citizens' Assembly resulted in significant policy turbulence, most notably through a major overhaul of the 2015 climate law. In the French case, by contrast, President Macron did not follow through on this commitment to submit the Convention's recommendations "unfiltered" to a referendum, to parliament, or to direct regulatory application. He rejected three of the 149 recommendations from the start, and the final version of the legislation designed to implement the convention's recommendations, the Climate and Resilience Bill, has been criticised by civil society for not going far enough to honour the spirit of those recommendations. These findings point to the limitations of

Table 2. Characteristics of Irish Citizens' Assembly and French Citizens Convention for Climate.

\begin{tabular}{lll}
\hline Design characteristics & Irish Citizens' Assembly & French Citizens Convention for Climate \\
\hline Mandate and framing & $\begin{array}{l}\text { Non-specific mandate, constrained } \\
\text { framing }\end{array}$ & Specific mandate, less constrained framing
\end{tabular}

Agency of participants

Largely top-down process

Process co-created with more agency given to participants 
focusing on the specific design characteristics of DMPs in order to understand their likely impact. The findings also emphasise the importance of context and contingency in assessing their contributions to the governance of climate transitions.

\section{Conclusions}

This article used the cases of the Irish Citizens' Assembly and French Citizens Convention for Climate to explore when and how climate-focused DMPs are likely to cause turbulence in the governance of climate transitions. The framework developed in Section 2 focused on central characteristics of DMPs, including their mandates and framing, the degree of agency given to participants, and the extent of policy coupling and integration. The empirical analysis showed that these factors matter, but that the broader context and contingent factors matter as well-perhaps even more.

The contrasting fates of the two cases point to a tension at the heart of the use of DMPs in climate change governance that ought to be investigated through further research. To what extent is the disruptive and pathbreaking potential of deliberative democratic innovations constrained by an inherent wariness on the part of governments to delegating agency to bodies over which they have limited control? Is there a trade-off between the degree of separation from government and the likelihood of follow-up on recommendations? A more distant relationship from the government may increase autonomy and independence over agenda and operation, but it may also result in government being less amenable to implementing recommendations from a DMPs.

It is too early to form a definite assessment on these questions, and future research ought to devote further attention to this area. The question of broader impact of DMPs is the least studied and understood in the literature. It is also among the most important topics in this field, and as more DMPs are implemented with varying design characteristics, and as more time passes, it will be important to conduct follow-up research to examine the extent to which, and the conditions under which, such processes shape the governance of climate transitions. As discussed in the introduction, the EGD aims to ensure a just transition by placing citizens at the centre of the climate transition, including by building on the growing experience of citizens' dialogues and assemblies across the EU. Given the scale of transformation across all sectors of economy and society envisaged as part of the EGD, citizen participation will indeed be central to its success or failure. In this context, policymakers and scholars ought to learn lessons from high-profile instances of democratic innovations such as those discussed above.

\section{Acknowledgments}

The author is grateful to Cáit Gleeson for research assistance in the preparation of this article.

\section{Conflict of Interests}

The author was a member of the expert advisory group to the Irish Citizens' Assembly 2016-2018 for its deliberations on the topic of climate change. Some of the analysis in this article draws on this experience.

\section{References}

Ansell, C., Sørensen, E., \& Torfing, J. (2020). The Covid-19 pandemic as a game changer for public administration and leadership? The need for robust governance responses to turbulent problems. Public Management Review, 23(7), 1-12. https://doi.org/10.1080/ 14719037.2020.1820272

Ansell, C., \& Trondal, J. (2018). Governing turbulence: An organizational-institutional agenda. Perspectives on Public Management and Governance, 1(1), 43-57. https://doi.org/10.1093/ppmgov/gvx013

Bauer-Babef, C. (2021). French lawmakers agree on final version of climate bill. Euractiv. https://www.euractiv. com/section/climate-environment/news/frenchlawmakers-agree-on-final-version-of-climate-bill

Blue, G. (2015). Public deliberation with climate change: Opening up or closing down policy options? Review of European Comparative \& International Environmental Law, 24(2), 152-159. https://doi.org/ 10.1111/reel.12122

Brown, M. B. (2006). Survey article: Citizen panels and the concept of representation. Journal of Political Philosophy, 14(2), 203-225. https://doi.org/10.1111/ j.1467-9760.2006.00245.x

Bryant, P., \& Stone, L. (2020). Climate assemblies and juries: A people powered response to the climate emergency. Shared Future.

Bua, A. (2019). Democratic innovations and the policy process. In S. Elstub \& O. Escobar (Eds.), Handbook of democratic innovation and governance (pp. 282-296). Edward Elgar.

Capstick, S., Demski, C., Cherry, C., Verfuerth, C., \& Steentjes, K. (2020). Climate change citizens' assemblies. Centre for Climate Change and Social Transformations.

Citizens' Assembly. (2018). Third report and recommendations of the Citizens' Assembly: How the state can make Ireland a leader in tackling climate change.

Citizens' Assembly. (n.d.-a). Establishment of the assembly-The Citizens' Assembly. https://20162018.citizensassembly.ie/en/About-the-CitizensAssembly/Background

Citizens' Assembly. (n.d.-b). Who are the membersThe Citizens' Assembly. https://2016-2018.citizens assembly.ie/en/About-the-Citizens-Assembly/Whoare-the-Members

Citizens Convention for Climate. (n.d.). FAQ. Citizens Convention for Climate. https://www.convention citoyennepourleclimat.fr/en/foire-aux-questions

DCCAE. (2019). Climate action plan to tackle climate 
breakdown. Department of Communications, Climate Action and Environment.

Devaney, L., Brereton, P., Torney, D., Coleman, M., Boussalis, C., \& Coan, T. G. (2020). Environmental literacy and deliberative democracy: A content analysis of written submissions to the Irish Citizens' Assembly on climate change. Climatic Change, 162, 1965-1984.

Devaney, L., Torney, D., Brereton, P., \& Coleman, M. (2020). Ireland's Citizens' Assembly on Climate Change: Lessons for deliberative public engagement and communication. Environmental Communication, 14(2), 141-146.

Dobbs, M., Gravey, V., \& Petetin, L. (2021). Driving the European Green Deal in turbulent times. Politics and Governance, 9(3), 316-326.

Dryzek, J. S. (1990). Discursive democracy: Politics, policy and science. Cambridge University Press.

Ehs, T., \& Mokre, M. (2021). Deliberation against participation? Yellow vests and grand débat: A perspective from deliberative theory. Political Studies Review, 19(2), 186-192.

Escobar, O., \& Elstub, S. (2017). Forms of mini-publics. New Democracy. https://newdemocracy.com.au/ wp-content/uploads/2017/05/docs_researchnotes_ 2017_May_nDF_RN_20170508_FormsOfMini Publics.pdf

European Commission. (2019). Communication from the Commission: The European Green Deal (COM(2019) 640 final).

Eymard, L. (2020). From the French Citizens' Convention on Climate to the Conference on the Future of Europe: A participatory science and democracy perspective. European Law Journal, 26(1/2), 136-140.

Farrell, D. M., Curato, N. C., Dryzek, J. S., Geißel, B., Grönlund, K., Marien, S., Niemeyer, S., Pilet, J.-B., Renwick, A., Rose, J., Setälä, M., \& Suiter, J. (2019). Deliberative mini-publics: Core design features (Working Paper 2019/5). Centre for Deliberative Democracy and Global Governance.

Fishkin, J. (1991). Democracy and deliberation: New directions for democratic reform. Yale University Press.

Font, J., Smith, G., Galais, C., \& Alarcon, P. (2018). Cherrypicking participation: Explaining the fate of proposals from participatory processes. European Journal of Political Research, 57(3), 615-636. https://doi.org/ 10.1111/1475-6765.12248

Gerwin, M. (2018). Citizens' assemblies: Guide to democracy that works. Open Plan Foundation.

Giraudet, L.-G., Apouey, B., Arab, H., Baeckelandt, S., Begout, P., Berghmans, N., Blanc, N., Boulin, J.-Y., Buge, E., Courant, D., Dahan, A., Fabre, A., Fourniau, J.-M., Gaborit, M., Granchamp, L., Guillemot, H., Jeanpierre, L., Landemore, H., Laslier, J.-F., . . . Tournus, S. (2021). Deliberating on climate action: Insights from the French Citizens' Convention for Climate. Hal. https://hal-enpc.archives-ouvertes.fr/hal-03119539

Goodin, R. E., \& Dryzek, J. S. (2006). Deliberative impacts:
The macro-political uptake of mini-publics. Politics \& Society, 34(2), 219-244. https://doi.org/10.1177/ 0032329206288152

Houses of the Oireachtas. (2019). Climate change: A cross-party consensus for action. Joint Committee on Climate Action, Houses of the Oireachtas.

Huffpost. (2021, February 28). La Convention citoyenne pour le climat étrille le projet de loi du gouvernement [Citizen's Climate Convention crushes government bill]. Le HuffPost. https://www.huffingtonpost.fr/ entry/la-convention-citoyenne-pour-le-climatetrille-le-projet-de-loi-du-gouvernement_fr_ 603b70acc5b6ff75ac3cfdb1

Karpowitz, C. F., Raphael, C., \& Hammond, A. S. (2009). Deliberative democracy and inequality: Two cheers for enclave deliberation among the disempowered. Politics \& Society, 37(4), 576-615. https://doi.org/ $10.1177 / 0032329209349226$

newDemocracy. (2019). Enabling national initiatives to take democracy beyond elections. https://www.new democracy.com.au/wp-content/uploads/2018/10/ New-Democracy-Handbook-FINAL-LAYOUTreduced.pdf

Niemeyer, S. (2013). Democracy and climate change: What can deliberative democracy contribute? Australian Journal of Politics and History, 59(3), 429-448.

Norris, P., \& Inglehart, R. (2019). Cultural backlash: Trump, Brexit, and authoritarian populism. Cambridge University Press.

OECD. (2020). Innovative citizen participation and new democratic institutions: Catching the deliberative wave-Highlights 2020. OECD Publishing.

Olsen, E. D. H., \& Trenz, H.-J. (2016). The micro-macro link in deliberative polling: Science or politics? Critical Review of International Social and Political Philosophy, 19(6), 662-679.

Pow, J. (2021). Mini-publics and the wider public: The perceived legitimacy of randomly selecting citizen representatives. Representation. Advance online publication. https://doi.org/10.1080/00344893.2021. 1880470

Saujot, M., Berghmans, N., Rüdinger, A., Treyer, S., Colombier, M., Brimont, L., \& Briand, Y. (2020). The Citizens' Climate Convention: 149 measures for a new vision of the transition. IDDRI. https:// www.iddri.org/sites/default/files/PDF/Publications/ Catalogue\%20lddri/Etude/ST0720-CCC\%20EN.pdf

Setälä, M. (2017). Connecting deliberative mini-publics to representative decision making. European Journal of Political Research, 56(4), 846-863.

Setälä, M., \& Smith, G. (2018). Mini-publics and deliberative democracy. In A. Bächtiger, J. S. Dryzek, J. Mansbridge, \& M. E. Warren (Eds.), The Oxford handbook of deliberative democracy (pp. 300-314). Oxford University Press.

Smith, G. (2003). Deliberative democracy and the environment. Routledge.

Stevenson, H., \& Dryzek, J. S. (2014). Democratizing 
global climate governance. Cambridge University Press.

Stop Climate Chaos. (2018, April 18). Citizens' Assembly report a mandate for revolutionising Ireland's climate policy. https://www.stopclimatechaos.ie/ news/2018/04/18/citizens-assembly-report-a- mandate-for-revolutioni

Thompson, N. (2019). The role of elected representatives in democratic innovation. In S. Elstub \& O. Escobar (Eds.), Handbook of democratic innovation and governance (pp. 255-268). Edward Elgar.

\section{About the Author}

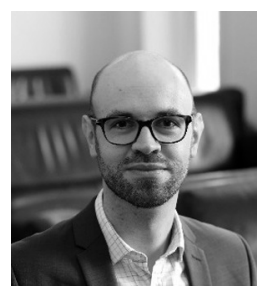

Diarmuid Torney is an associate professor in the School of Law and Government at Dublin City University. His research focuses on climate change politics and governance. He is co-director of Dublin City University's Centre for Climate and Society and director of the MSc Climate Change: Policy, Media and Society. 